presumably takes place via the vena azygos through oesophageal and other intercostophrenic veins or short venae communicantes to the inferior vena cava.

The krypton injected into the spleen as a bolus could be recovered from the radial artery as late as five minutes afterwards, indicating marked overdistension and retardation in the portal pool.

A summary of the various haemodynamic shunts in portopulmonary bilharziasis is presented in Fig. 6 .

We are grateful to the National Research Council and Dr. S. Hashish, whose active co-operation in the nuclear physics department made the work with krypton possible.

\section{REFERENCES}

Ashba, J. (1959). Thesis, University of Alexandria.

El-Hawari (1958). Gaz. Kasr-El-Aini Fac. Med., 24, 234.

Foda, M. T. (1959). Thesis, University of Alexandria.

Fritts, H. W., Hardewig, A., Rochester, D. F., Durand, J., and Cournand, A. (1960). F. clin. Invest., 39, 1841.

Hanson, J. S. (1961). f. Amer. med. Ass., 176, 16.

Keys, A., and Snell, A. M. (1938). 7. clin. Invest., 17, 59.

Schlant, R. C., Tsagaris, T. J., Robertson, R. J., Winter, T. S., and Edwards, F. K. (1962). Amer. Heart f., 64, 512.

Zaky, H. A. (1952). Dis. Chest, 21, 194.

- El-Heneidy, A. R., and Foda, M. T. (1962). Brit. med. F., 1, 367. - Tawfick, I. M., Gemei, Y., and Khadr, A. A. (1959): Dis. Chest, 36, 164.

\title{
Spontaneous Intraperitoneal Haemorrhage During Pregnancy : Report of Three Cases
}

\author{
W. A. HANNA,* M.B., F.R.C.S.ED.; T. J. M. MYLES, † M.D., M.R.C.o.G.
}

Brit. med. F., 1964, 1, 1024-1026

Spontaneous intraperitoneal haemorrhage during pregnancy or the puerperium, although relatively rare, may be due to a variety of causes and may originate from any intra-abdominal artery or vein, or a blood-filled viscus. Rupture of a splenicartery aneurysm is perhaps the best-known source of such bleeding, but the basic features and principles of management are similar whether the site of bleeding is in the upper or the lower abdomen. It is evident from the literature that there is still often a considerable delay in diagnosis, which adversely affects the results of treatment. Three cases treated in Banbridge Hospital and Lurgan and Portadown Hospital, and reported below, illustrate different sources of haemorrhage. Obstetrical cases in these two neighbouring hospitals are under the overall care of the one consultant, although in Banbridge Hospital general practitioners look after their own normal cases. Both hospitals have a combined emergency surgical duty rota.

\section{Case 1}

A married woman aged 27 , gravida-2, para-0, was admitted to Banbridge Hospital on 1 April 1961 when 23 weeks pregnant. Her first pregnancy in 1960 had ended in abortion at 10 weeks. She had awakened from sleep with severe abdominal pain and had called her doctor, who found her blood-pressure to be $90 / 50 \mathrm{~mm}$. Hg but without tachycardia. There was generalized abdominal tenderness and the uterus corresponded in size to a 22 -weeks pregnancy. The foetal heart could be heard. Immediate admission to hospital was arranged.

On arrival at hospital the patient's colour was good, the pulse rate 100 , and the systolic pressure had risen to $120 \mathrm{~mm}$. $\mathrm{Hg}$. The uterine fundus was at the level of the umbilicus and the foetal heart was audible. There was generalized abdominal tenderness, maximum in both iliac fossae, with guarding and rebound tenderness. A provisional diagnosis of intraperitoneal bleeding, possibly from a splenic-artery aneurysm, was made, blood transfusion was started and arrangements were made for laparotomy.

At operation the abdomen was entered through a left paramedian incision and the peritoneal cavity was found to contain 2 pints $(1,140$

\footnotetext{
* Lately Senior Surgical Registrar, Banbridge Hospital, Northern Ireland. At present Senior Tutor, Department of Surgery, Queen's University, Belfast.

† Consultant Obstetrician and Gynaecologist, North Armagh, Banbridge and Dromore Hospital Groups, Northern Ireland.
}

ml.) of blood and blood clot. The site of bleeding was a vein on the anterior surface of the uterus and a small tear was present in the peritoneum overlying the bleeding-point. The bleeding was controlled by suturing the area with interrupted catgut sutures over gel foam soaked in thrombin. Blood and blood clot were cleared from the peritoneal cavity and the abdomen was then closed in layers without drainage. A total of 2 pints $(1,140 \mathrm{ml}$.) of blood was given before and during operation and the patient's post-operative condition was satisfactory. Recovery afterwards was uneventful and she was discharged home on 15 April.

The remainder of her pregnancy was normal, and on 29 June she had a normal delivery of a living child weighing $7 \mathrm{lb} .5 \mathrm{oz}$. $(3,315$ g.). Subsequent inquiry from another hospital in which she had been curetted after her previous abortion showed that there had been no complications at that time and nothing to suggest perforation of the uterus at operation. No history of trauma during the present pregnancy could be obtained, and it must be presumed that the intraperitoneal bleeding was spontaneous.

\section{Case 2}

A married woman aged 38, gravida-6, para-5, collapsed at home with sudden severe left-sided abdominal pain on 26 June 1961 . She was then 10 days past her expected date of confinement and had been feeling well until one week previously, when she had developed a cough and slight continuous pain in the left loin. Her previous pregnancies and labours had been normal.

The obstetric flying squad was called, and on arrival found the patient to be severely shocked, pale, cold, and cyanosed, with stertorous breathing. The pulse was thready, rate 140, and the systolic pressure was $65 \mathrm{~mm}$. Hg. Crepitations were heard at both lung bases. The uterus corresponded in size to a term pregnancy and was contracting. The presentation was vertex with the head engaged, and the foetal heart could be heard. There was no tenderness over the uterus, but tenderness was marked in the left flank. There was no revealed vaginal bleeding.

Blood transfusion was started immediately and 2 pints $(1,140 \mathrm{ml}$.) of blood was given rapidly, after which the blood-pressure rose to $115 / 75 \mathrm{~mm}$. Hg and the pulse rate dropped to 120 . A third pint $(570 \mathrm{ml}$.$) of blood was begun and the patient was transferred to the$ Lurgan and Portadown Hospital, 7 miles $(11 \mathrm{~km}$.) distant. During the journey the blood-pressure started to fall again and on admission to hospital the systolic pressure was $75 \mathrm{~mm}$. $\mathrm{Hg}$. Further blood was transfused and the patient's condition improved. By this time the foetal heart was no longer audible. 
A provisional diagnosis of concealed accidental haemorrhage was made, though the case was regarded as atypical and the possibility of a ruptured splenic-artery aneurysm was noted at the time. Examination under anaesthesia revealed a soft cervix, dilated to admit three fingers, with a bulging bag of membranes. The presentation was vertex, right occipito-posterior, and the pelvic capacity was good. Artificial rupture of the forewaters was performed and the liquor which escaped was heavily stained with meconium. Two and a half hours later the patient had a normal delivery of a stillborn baby weighing $9 \mathrm{lb} .14 \mathrm{oz}$. $(4,480 \mathrm{~g}$.$) . The placenta was normal, with$ no suggestion of retroplacental clot. At this stage the patient's blood-pressure was $90 / 60 \mathrm{~mm}$. $\mathrm{Hg}$, and pulse rate 120 , and this condition was maintained for one and a half hours after which the pulse rose to 140 and the systolic pressure dropped to $75 \mathrm{~mm}$. $\mathrm{Hg}$. Blood transfusion had been continued after delivery, and, although 6 pints (3.4 litres) of blood had been given, the patient's general condition was obviously deteriorating and she complained of pain across the upper abdomen. A tender fullness was palpable in the left hypochondrium and there was generalized abdominal tenderness. A diagnosis of ruptured splenic-artery aneurysm was made and laparotomy decided upon.

At operation the abdomen was opened through a long left paramedian incision. A large amount of free blood was present in the peritoneal cavity. The uterus, both tubes, and both ovaries appeared normal. A large retroperitoneal haematoma containing approximately 3 pints (1.7 litres) of blood was found in the region of the left kidney, extending towards the right side and downwards into the pelvis. There was no evidence of haemorrhage into the lesser sac. The descending colon was mobilized by incision of the peritoneum along its lateral aspect, and then swept medially, thus exposing the haematoma. After clearing out the blood clot, a vein draining the left suprarenal was found to be bleeding and the gland itself was disorganized by clot. The vein was ligated, using catgut on an atraumatic needle, and some sutures had to be inserted into the substance of the gland in order to control the bleeding completely. Blood and blood clot were cleared from the abdominal cavity, and the abdomen was closed in layers after inserting a corrugated-rubber drain to the region of the suprarenal gland through a separate stab incision. A further 4 pints (2.3 litres) of blood was transfused during operation; when the patient left the operating-theatre her systolic pressure was $90 \mathrm{~mm}$. $\mathrm{Hg}$ and her pulse 140. Hydrocortisone was given intravenously, being continued over a period of 48 hours by intramuscular injection. The blood transfusion was maintained and the blood-pressure gradually rose to $150 / 90 \mathrm{~mm}$. $\mathrm{Hg}$. A total of 12 pints (6.8 litres) of blood was given before the transfusion was discontinued.

Post-operatively the patient's chest infection became worse. Streptomycin and penicillin were administered daily and the amount of hydrocortisone was gradually reduced. Her condition continued to improve and she was satisfactory when discharged from hospital on 10 July. She was well when seen at the postnatal clinic on 5 September 1961.

\section{Case 3}

A married woman aged 27, gravida-4, para-1, was admitted to the general practitioner maternity unit at Banbridge Hospital on 29 December 1961. She was then two weeks past her expected date of confinement. She had had a normal delivery in 1959, and since then had had two miscarriages, at 14 weeks and 16 weeks. A Shirodkar operation had been performed on 15 June 1961. It had been explained to the patient that admission would be required when she was 38 weeks pregnant, but she had ignored attempts to get her to attend the antenatal clinic.

On the day of admission two braided nylon sutures were removed from the cervix. The presentation was found to be breech, left sacro-anterior, and the foetal heart was audible. Labour started 12 hours later, but after four hours in the first stage the foetal heart became irregular and soon after this stopped suddenly. Examination showed the cervix to be fully dilated. A leg was brought down and breech extraction was performed, the aftercoming head being delivered with forceps. The baby was stillborn and weighed $7 \mathrm{lb} .8 \mathrm{oz}$. (3,400 g.). The placenta and membranes were normal and complete and there was no post-partum haemorrhage. The blood-pressure after delivery was $115 / 80 \mathrm{~mm}$. Hg.

Two hours after delivery the patient complained of sudden and severe pain in the epigastric region, radiating to the right hypo- chondrium. A short time later she experienced pain in both shoulder-tips and later had severe pain in the left side of her chest, but it was not until three hours after the onset of the initial epigastric pain, when the patient collapsed suddenly, that her general practitioner was notified. At this stage there was marked tachycardia and the blood-pressure was $70 / 60 \mathrm{~mm}$. $\mathrm{Hg}$, later falling to $60 / 50$ $\mathrm{mm}$. $\mathrm{Hg}$, and she was looking pale. On account of the chest pain a diagnosis of pulmonary embolism was considered, and a consultant physician was asked to see her. He excluded a pulmonary embolism and cardiac infarction, and suggested that she might have intraperitoneal bleeding. At this stage the consultant obstetrician was called. There was generalized abdominal tenderness, most marked in the left hypochondrium, with rebound tenderness, shifting dullness, and absent bowel sounds, but no abdominal distension. A diagnosis of ruptured splenic-artery aneurysm was made and blood transfusion was started while preparations were made for laparotomy.

At operation under general anaesthesia the abdomen was entered through a long left paramedian incision. About 3 pints $(1.7$ litres) of blood was found in the general peritoneal cavity and the lesser sac was distended with blood. The spleen was mobilized by division of the lieno-renal ligament and brought forward into the wound. It was found that blood was coming from a tear in the splenic artery near the hilum but no aneurysm was seen. The splenic pedicle was clamped and ligated proximal to the site of bleeding and splenectomy was performed. The abdomen was closed in layers without drainage, after clearing out blood and blood clot and excluding the presence of any other pathological condition. Four pints (2.3 litres) of blood was given before and during operation, and on leaving the theatre the patient's systolic pressure was 110 $\mathrm{mm}$. $\mathrm{Hg}$, and her pulse 90 . Intravenous fluids were continued for two days until the return of bowel sounds. The remaining postoperative course was uneventful and the patient was discharged home on the thirteenth day after operation. Post-natal examination six weeks later revealed no abnormality. Pathological examination of the removed spleen showed no aneurysm of the splenic artery. A small cavernous haemangioma $1 \mathrm{~cm}$. in diameter was present on the side opposite to the hilum.

\section{Discussion}

\section{Frequency and Site of Spontaneous Haemorrhage}

Ellis, Griffiths, and MacIntyre (1958) found that ruptured ectopic pregnancy or follicular cyst $(68 \%)$ and trauma $(23 \%$ ) were the commonest causes of their 129 cases of haemo peritoneum. However, spontaneous rupture of intra-abdominal blood-vessels, though considered rare, is a very definite clinical entity (Bruce, 1937). The Cumulated Index Medicus for 1961 lists 13 papers dealing with splenic-artery aneurysms alone. Arteries, veins, or a blood-filled viscus such as the spleen may rupture, accounting for severe intraperitoneal blood loss.

If haemorrhage is from an artery the wall at the site of rupture may be apparently normal, or may show degeneration of the media or aneurysmal dilatation. Such aneurysms can occur in the younger age-group. Schnitker and Bayer (1944) found that nearly $25 \%$ of 580 dissecting aneurysms of the aorta occurred in patients under the age of 40 . Approximately $35 \%$ of these were in females, of whom just under $50 \%$ were pregnant at the time of rupture. Sherlock and Learmonth (1942), reviewing aneurysms of the splenic artery, stated that $20 \%$ of female patients were pregnant when the aneurysm ruptured Pedowitz and Perell (1957), in an extensive review, gave the relative frequency of rupture during pregnancy of the aneurysms collected by them as follows: aorta (48 dissecting, 12 saccular); splenic artery (35); renal artery (10); iliac arteries (3).

Bleeding from intra-abdominal veins may also occur during pregnancy. Rupture of the splenic vein has been reported (Eckerling, Goldman, and Yado, 1962), and Hodgkinson and Christensen (1950) collected 72 cases of rupture in some part of the utero-ovarian venous system, and added three of their own. These authors pointed out that, depending on the site of rupture, the haemorrhage could be retroperitoneal or intraperitoneal or combined. Choudhuri (1961) has shown that a uterine 
fibroid may be the source, of intraperitoneal bleeding in pregnancy.

Apart from blood-vessels the spleen may be the source of spontaneous haemorrhage. In only 16 of the 44 cases of rupture of the spleen during pregnancy reviewed by Sparkman (1958) was there any history of even minimal trauma.

In addition to our reports of bleeding from a uterine vein, a suprarenal vein, and an apparently normal splenic artery, we have collected other cases of spontaneous haemorrhage associated with pregnancy which have occurred in Northern Ireland during the last 10 years. These include four cases of rupture of an apparently normal splenic artery or splenic-artery aneurysm (Boyd, 1957 ; Gallagher and Hudson, 1954 ; C. G. Irwin, personal communication, 1963 ; C. H. G. Macafee, personal communication, 1963) and rupture of a haemangioma of spleen (Campbell, 1962), a uterosacral vein (Macafee, personal communication, 1963), and broad-ligament varices (J. A. Price, personal communication, 1963). Macafee and Magee (1956) reported two cases of intraperitoneal haemorrhage after normal delivery, where a haematoma which had formed in the posterior vaginal fornix ruptured through the peritoneum.

Closely allied to these cases of intraperitoneal haemorrhage, in that the basic lesion is likely to have been a rupture of an intra-abdominal blood-vessel, are other cases of spontaneous retroperitoneal haemorrhage. These include several broadligament haematomata and retroperitoneal bleeding from the region of the left kidney (W. S. Campbell, personal communication, 1963), but in these the overlying peritoneum had remained intact.

Although this series of cases traced in Northern Ireland is probably too small and incomplete to be of any value in assessing the incidence of this particular emergency, the fact that these cases have all oceurred in this relatively small province with a population of just over $1,425,000$ may lend force to our thesis that the condition merits serious consideration in the differential diagnosis of many emergencies associated with pregnancy.

\section{Summary}

Three cases of intraperitoneal haemorrhage associated with pregnancy are described. This is a definite though relatively rare complication in pregnant patients.

The bleeding may be from any intra-abdominal artery or vein, or the spleen. Although one well-documented review indicates that aortic aneurysms are the most likely to rupture during pregnancy, the majority of reports, including the present one, suggest that haemorrhage is commoner from spleen or splenic vessels, pelvic veins, and varicosities.

When intraperitoneal haemorrhage occurs in the pregnant patient obstetric causes of pain and shock, especially concealed accidental haemorrhage, may lead to delay in diagnosis.

Management depends on a clinical awareness of the condition and an early diagnosis, adequate resuscitation of the patient, and prompt laparotomy to deal with any source of haemorrhage.

We wish to thank Mr. J. H. Balmer, Mr. H. W. Gallagher, and Dr. R. A. Pyper for their help in the management of the reported cases, and gynaecological colleagues for details of other cases referred to in this article. Our thanks are also due to Professor C. H. G. Macafee for his help and encouragement in the preparation of this paper.

\section{REFERENCES}

Boyd, G. (1957). Irish 7. med. Sci., 6, 516

Bruce, J. (1937). Lancet, 1, 1451.

Bruce, J. (1937). Lancet, 1, 1451.

Campbell, W. S. (1962). F. Obstet. Gynaec. Brit.

Eckerling, B., Goldman, J. A., and Yado, S. (1962). Amer. F. Surg., 103, 636.

Ellis, H., Griffiths, P. W. W., and MacIntyre, A. (1958). Brit. F. Surg., 45, 606.

Gallagher, H. W., and Hudson, K. (1954). Brit. med. f., 2, 1209.

Hodgkinon, C. Obstet.

Gynec., 59, 1112 . Cwlth, 63, 349 .

Pedowitz, P., and Perell, A. (1957). Amer. F. Obstet. Gynec., 73, 720.

Schnitker, M. A., and Bayer, C. A. (1944). Ann. intern. Med., 20, 486. Sherlock, S. P. V., and Learmonth, J. R. (1942). Brit. F. Surg., 30, 151. Sparkman, R. S. (1958). Amer. Y. Obstet. Gynec., 76, 587

\section{Medical Memoranda}

\section{Behçet's Disease and Carditis}

Brit. med. F., 1964, 1, 1026-1027

Behcet's syndrome of recurrent oral and genital ulceration with relapsing iritis was first described in 1937 and has since expanded to include thrombophlebitis (France et al., 1951), neurological complications (Pallis and Fudge, 1956), and polyarthritis (Strachan and Wigzell, 1963). Cardiac manifestations have been described only rarely, and the world literature contains only two case reports (Stucchi and Vollenweider, 1958 ; Oshima et al., 1963). The following is the first report of a case of acute carditis with Behçet's disease.

\section{CASE REPORT}

A 43-year-old housewife was admitted to hospital in March, 1963, with a one-day history of pain and swelling of the right leg. She had no other symptoms, but gave a history of "rheumatic fever" at 16. Examination showed her to be an anxious woman having a hot swollen right lower leg with pain in the calf and on dorsiflexion of the foot. Her pulse was 80 and blood-pressure 140/90. There were no murmurs. A fibroid uterus was palpable. Her haemoglobin was 13 g./100 ml., white blood count 5,600/c.mm., and erythrocyte sedimentation rate (Westergren) $6 \mathrm{~mm}$. in one hour. A diagnosis of thrombophlebitis was made and she was treated with phenindione for three weeks. She made a good recovery and went home.

Four weeks later she felt ill, had a sore throat, and simultaneously developed painful ulcers of the mouth and vulva; the ulcers spread and became confluent in places. A week later her right eye was red and painful for three days. Hydrocortisone pellets did not improve the condition of her mouth, so she was readmitted.

She was febrile $\left(99^{\circ}\right.$ F. $; 37.2^{\circ}$ C.) with injection of the fauces and around the right cornea. Pulse was 100 and B.P. 150/90. Investigation showed E.S.R. $55 \mathrm{~mm}$. in one hour, haemoglobin 10.8 g./100 ml., W.B.C. 9,900/c.mm.; plasma proteins 6.7 g./ $100 \mathrm{ml}$. (albumin $3.7 \mathrm{~g}$., globulin $3 \mathrm{~g}$.). Chest $x$-ray examination showed a calcified focus in the right upper lobe. Three days later her left knee became hot and painful with gross hydrarthrosis, and on the next day she became very ill with a fever of $100^{\circ} \mathrm{F}$. $\left(37.8^{\circ}\right.$ C.), a pulse of 120 , and a B.P. of $100 / 60$. A transient macular rash of the face was observed. On the fifth day the arthritis moved from the left knee to the right knee. A soft presystolic gallop rhythm was heard over the left ventricle. A throat swab grew $\beta$-haemolytic streptococci. Antistreptolysin titre was 100 units. Latex flocculation tests for rheumatoid arthritis and lupus erythema- 